chiefly or wholly with the fast component. It would be of great interest to separate electrophoretically a pure specimen of this component and to ascertain whether or not this is the case. The chief difficulty lies in achieving a sufficiently good separation of pure material from the amounts of the preparations available.

Mobility determinations were made at $\mathrm{pH} \mathbf{1 0 . 2}$ and 7.4. The results are shown in Table 7. They are uncorrected for buffer viscosity, and are also liable to contain errors caused by the inability to maintain a very steady current, owing to large fluctuations of the mains supply.
Table 7. Mobilities of components present in collagenase preparations, expressed in cm./sec./V./ cri. $\times 10^{-5}$

\begin{tabular}{cccc} 
pH & \multicolumn{3}{c}{ Component } \\
\cline { 2 - 4 } $10 \cdot 2$ & Fast & Middle & Slow \\
7.4 & -7.29 & -5.96 & -5.41 \\
-5.25 & -4.37 & -3.76
\end{tabular}

The above results have been confirmed qualitatively by runs on other batches of collagenase preparations.

\title{
REFERENCES
}

Anson, M. L. (1938). J. gen. Physiol. 22, 79.

Bergmann, M. (1933). Nature, Lond., 131, 698.

Bergmann, M. \& Fruton, J. S. (1937). J. biol. Chem. 117, 189.

Bergmann, M. \& Fruton, J. S. (1941). Advances in Enzymology, 1, 63-96. New York: Interscience Publishers, Inc.

Campbell, D. H. \& Fourt, L. (1939). J. biol. Chem. 129, 385.

Clark, W. M. (1928). The Determination of Hydrogen Ions, 3rd ed. London: Baillière, Tindall and Cox.

Evans, D. G. (1945). Lancet, 249, 478.

Grassmann, W. \& Heyde, W. (1929). Hoppe-Seyl. Z. 183, 32.

Grassmann, W., Schoenebeck, O. \& Auerbach, G. (1932). Hoppe-Seyl. Z. 210, 1.

Linderstrøm-Lang, K. (1928). Hoppe-Seyl. Z. 173, 32.
Macfarlane, R. G. \& MacLennan, J. D. (1945). Lanicet, $249,328$.

Markham, R. (1942). Biochem. J. 36, 790.

Maschmann, E. (1937). Biochem. Z. 295, 1.

Maschmann, E. (1938a). Biochem. Z. 295, 351.

Maschmann, E. (1938b). Biochem. Z. 297, 284.

Maschmann, E. (1938c). Biochem. Z. 300, 89.

Michaelis, L. (1931). Biochem. Z. 234, 139.

Oakley, C. L., Warrack, G. H. \& van Heyningen, W. E. (1946). J. Path. Bact. 58, 229.

Pope, C. G. \& Stevens, M. F. (1939). Biochem. J. 33, 1070.

Richardson, G. M. (1934). Proc. roy. Soc. B, 115, 121.

Robb-Smith, A. H. T. (1945). Lancet, 249, 362.

Sen, S. N. (1942). Ind. J. med. Res. 30, 335.

van Heyningen, W. E. (1948). Bischem. J. 42, 127.

\section{The Colorimetric Determination of Stilboestrol and Dienoestrol}

\author{
BY F. L. WARREN, F. GOULDEN AND ALICE M. ROBINSON \\ Chester Beatty Research Institute, The Royal Cancer Hospital (Free), London, S.W. 3, \\ and Pathology Department, St Bartholomew's Hospital, London, E.C. 1
}

(Received 12 May 1947)

A preliminary account has been given (Warren \& Goulden, 1945) of investigations that have been carried out on methods proposed for chemical assay of synthetic oestrogens. Two methods were studied. One (Dingemanse, 1939) is based upon the development of a red colour by the oestrogen in the presence of antimony pentachloride; the other (Malpress, 1945) relies on the measurement of the yellow colour obtained by nitration of the oestrogen followed by neutralization. The antimony reaction proved to be very sensitive. By its use the instability of dienoestrol in solution was demonstrated. On the other hand, stilboestrol (4:4'-dihydroxy- $\alpha \beta$-diethylstilbene) appears to be quite stable in solution in a variety of solvents. It was subsequently found (Wilder Smith \& Williams, 1945) that the oestrogenic activity of solutions of dienostrol shows a similar decrease with time. Hence, chromogenic activity towards antimony pentachloride and oestrogenic activity appear to run parallel. On the other hand, solutions of dienoestrol that show very low activity in the antimony pentachloride reaction continue to react strongly in Malpress's test.

In the present paper details of these experiments are given, together with the results of some attempts to apply the antimony reaction to the estimation of synthetic oestrogens in urine of subjects treated therapeutically with these substances. 


\section{EXPERIMENTAL}

\section{The antimony pentachloride reaction}

In the original description of this reaction (Dingemanse, 1939), few details are given. Stilboestrol dissolved in chloroform (washed free from ethanol) was treated with a $50 \%(\mathrm{v} / \mathrm{v})$ solution of antimony pentachloride in the same solvent. Difficulty was experienced in obtaining reproducible results by this simple technique, and a systematic study of the factors influencing colour development was undertaken. rapidly, there was almost complete precipitation of a red compound. Trichloroethylene also had to be excluded since it reacts with antimony pentachloride and develops colour. Ethylene dichloride was finally chosen as being the most suitable of the solvents tried. Good colour development occurs and the colour is much more stable than in chloroform. An additional practical advantage is that a good commercial grade of this solvent can be used without preliminary purification. Previous washing with water or with alkali followed by drying and distillation effected no improvement in colour stability.

Table 1. Colour reactions of substituted stilbenes with antimony pentachloride

Substance

Hexoestrol (HO. $\mathrm{C}_{6} \mathrm{H}_{4}$. CHEt. CHEt. $\mathrm{C}_{6} \mathrm{H}_{4} . \mathrm{OH}$ )

Dienoestrol (HO. $\left.\mathrm{C}_{6} \mathrm{H}_{4} \cdot \mathrm{C}(: \mathrm{CHMe}) \cdot \mathrm{C}(: \mathrm{CHMe}) \cdot \mathrm{C}_{6} \mathrm{H}_{4} \cdot \mathrm{OH}\right)$

Stilboestrol (HO.C ${ }_{6} \mathrm{H}_{4}$. CEt: CEt. $\mathrm{C}_{6} \mathrm{H}_{4} \cdot \mathrm{OH}$ )

4:4'-Dihydroxy- $\alpha \beta$-dimethylstilbene

4:4'-Dihydroxy- $\alpha-n$-propylstilbene

4:4'-Dihydroxy- $\alpha$-methyl- $\beta$ - $n$-propylstilbene

4:4'-Dihydroxy- $\alpha$-ethyl- $\beta$-cetylstilbene

4-Methoxy- $\alpha \beta$-diethylstilbene

Stilbene

$\alpha$-Ethylstilbene

Triphenylethylene

$\alpha$-( $p$-Hydroxyphenyl)stilbene

Triphenylmethylethylene

4:4'-Diacetylstilbene

4:4'-Diacetyl- $\alpha \beta$-diethylstilbene

(a) Specificity. Many stilbene derivatives develop colour in the presence of antimony pentachloride dissolved in ethanol-free chloroform (small amounts of ethanol change, or destroy, the colour). In Table 1 the results of qualitative tests on a range of substituted stilbenes are shown. The presence of at least one ethylenic bond appears to be essential for chromogenic power (hexoestrol gives practically no colour), but the colour is modified by the presence of substituent groups in the molecule. In general, the presence of a hydroxyl group tends to deepen the colour towards the red end of the spectrum. Weight for weight, stilboestrol develops more colour than does dienoestrol. For quantitative measurement of stilboestrol and of dienoestrol (using a Spekker photoelectric absorptiometer) Ilford Spectrum Green filter no. 604 was found to be the most suitable.

(b) Solvent. The preliminary experiments were carried out in chloroform (B.P. grade) which had been thoroughly washed with water to remove the small quantity of ethanol normally incorporated. The chloroform was dried over calcium chloride and distilled before use. Good colour development was obtained on mixing a chloroform solution of antimony pentachloride with a chloroform solution of the oestrogen, but the colour faded rapidly. In order to overcome this difficulty other chlorinated solvents were tried. Carbon tetrachloride was unsuitable since, although a red colour developed

\section{Colour}

Transient yellow
Red-brown
Red
Red
Orange
Red
Red
Red-green
Yellow
Brown
Yellow-brown
Brown-orange
Olive-green
No colour
No colour

(c) Concentration of antimony pentachloride. The intensity of the final colour depends on the concentration of antimony pentachloride present. In order to establish the conditions for maximal colour

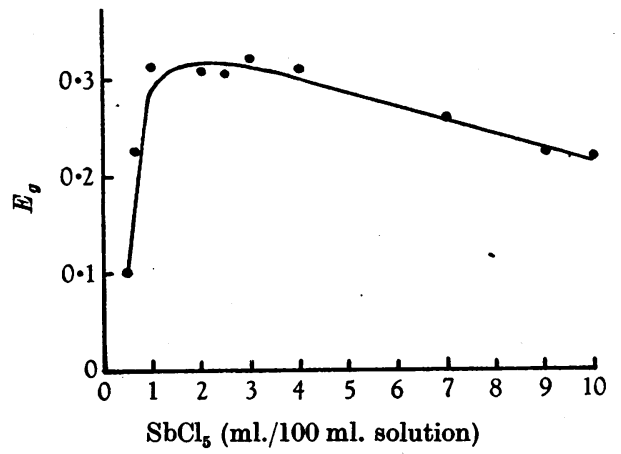

Fig. 1 Stilboestrol-SbCl $\mathrm{Sb}_{5}$ reaction. Influence of variation in concentration of $\mathrm{SbCl}_{5}$ on the final intensity of colour. $E_{\sigma}$ is the extinction of the solution in green light.

development, $1 \mathrm{ml}$. of a solution of stilboestrol was treated with $9 \mathrm{ml}$. of solutions of antimony pentachloride of varying strengths. The results of these experiments are shown in Fig. 1. It will be seen that maximum colour is obtained when the final antimony pentachloride concentration lies between 1 and 
$4 \%(\mathrm{v} / \mathrm{v})$. A reagent containing $3 \mathrm{ml}$. of antimony pentachloride dissolved in $100 \mathrm{ml}$. of ethylene dichloride was finally adopted as standard. For estimations of stilboestrol or dienoestrol, $9 \mathrm{ml}$. of this reagent were added to $1 \mathrm{ml}$. of a solution of the oestrogen in ethylene dichloride. Ordinary reagent quality antimony pentachloride (B.D.H.) was found quite satisfactory without any special purification, but the solution in ethylene dichloride employed as reagent should be freshly prepared immediately before use.

(d) Time. With dienoestrol, maximum colour development occurs immediately on mixing with the reagent. With stilboestrol the colour increases during

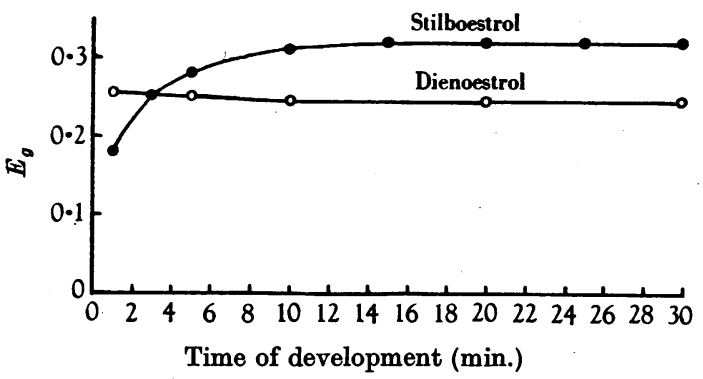

Fig. 2. Stilboestrol and dienoestrol colour reaction with $\mathrm{SbCl}_{5}$. Effect of time of development on the final intensity of colour. $E_{g}$ as in Fig. 1.

the first $10 \mathrm{~min}$. and then reaches a maximum. The influence of time on colour development is illustrated in Fig. 2. As a routine, colour measurements were made 15 min. after mixing the oestrogen with the reagent.

(e) Temperature. The rate of development of maximal colour varies with temperature. Although the temperature coefficient is not large it was found convenient to standardize the conditions by maintaining the solutions at $30^{\circ}$ during the $15 \mathrm{~min}$. period of colour development.

\section{The Malpress nitro reaction}

A comparison was made of this method (Malpress, 1945) with the antimony pentachloride method. A detailed account of the application of the method has been given by Malpress, and only points of major interest will be mentioned here.

(a) Specificity. The nitro reaction (a general one for phenols) is comparatively non-specific, both as regards substances giving the reaction and as regards colour developed.

(b) Spectral absorption characteristics and sensitivity. In Fig. 3 are shown approximate light absorptions (measured on a Hilger Spekker absorptiometer fitted with Ilford Spectrum filters) of oestrogens treated with antimony pentachloride and of dienoestrol treated according to Malpress's procedure. It will be seen that, whereas the antimony reagent develops a red colour with a definite maximum absorption in the green, the nitro reaction leads to an orange colour showing rather general absorption at the violet end of the spectrum.

An Ilford Spectrum blue-green (no. 603) filter gave the highest values and most sensitive slope to the calibration curve for the nitro reaction. When this filter is used the sensitivity of the nitro-reaction determination is about one twentieth that of estimations by the antimony reagent.

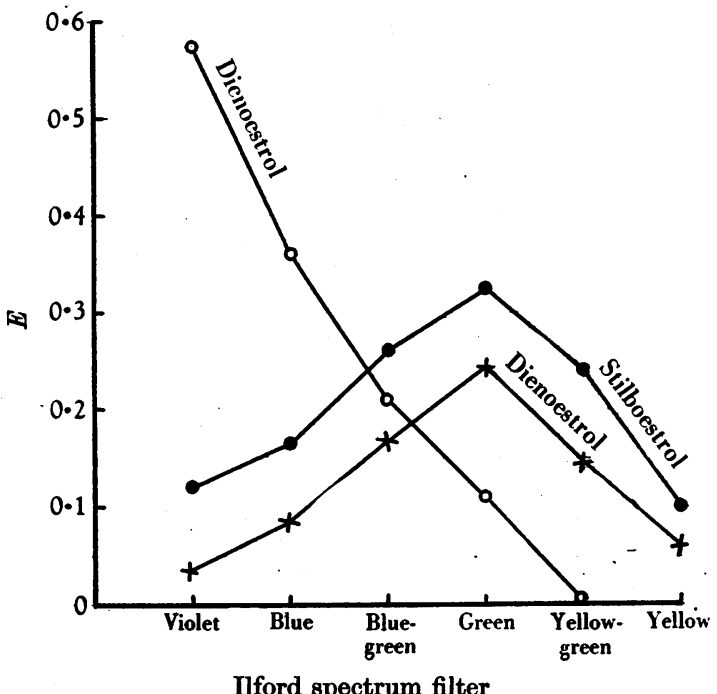

Fig. 3. Comparison of $\mathrm{SbCl}_{5}$ reaction (stilboestrol and dienoestrol) and the nitro reaction (dienoestrol). Light absorption curves of the coloured products of these reactions. $\mathrm{SbCl}_{5}$ reaction, oestrogen concentration $2 \mu \mathrm{g} . / \mathrm{ml}$. Nitro reaction, oestrogen concentration $20 \mu \mathrm{g} . / \mathrm{ml}$.

Application of the antimony pentachloride reaction to the determination of synthetic oestrogens in chloro- form and in ethylene dichloride solutions

Since the ultimate objective of this work was the devising of a method for colorimetric determination of synthetic oestrogens in extracts prepared from human urine, the behaviour of these substances in solvents suitable for urine extraction (e.g. chloroform and ethylene dichloride) was studied. Since extraction of oestrogens from urine would involve their exposure to air, light, and normal room temperatures, no attempt was made to protect the oestrogen solutions from such influences.

Stock solutions of stilboestrol, dienoestrol, and isodienoestrol were prepared and allowed to stand in colourless glass flasks under ordinary laboratory conditions. Exposure to direct sunlight was avoided. Samples were withdrawn, initially and at intervals, and their chromogenic power towards the antimony reagent determined. The initial value, determined as soon as possible after solution had been achieved, was taken as indicating the full chromogenic power 
of the oestrogen initially present. Later values were recorded as percentages of this initial reading. The curves shown in Fig. 4 were constructed from mean

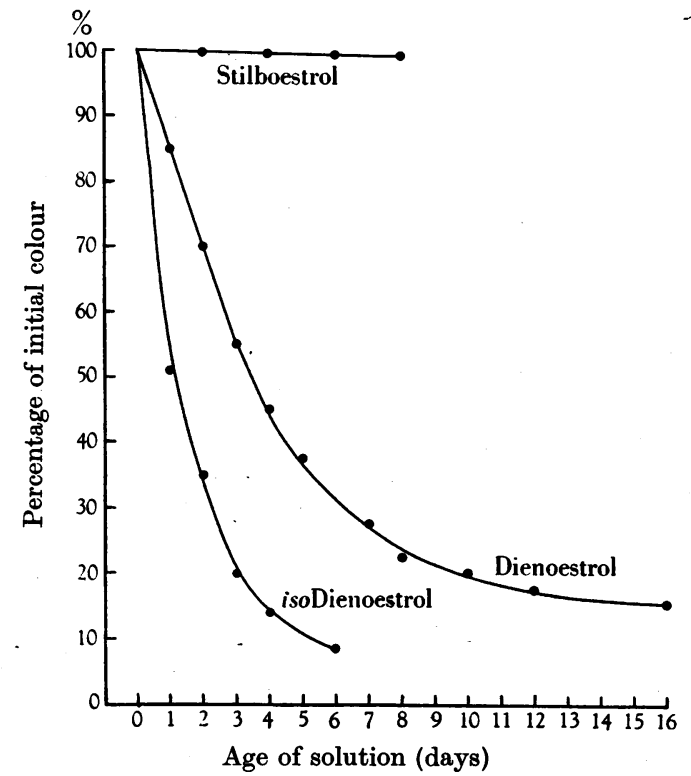

Fig. 4. Effect of age of solution of synthetic oestrogens on the reaction with $\mathrm{SbCl}_{5}$. Chromogenic power expressed as percentage of initial colour value.

values determined in a number of separate experiments. It is clear that dienoestrol and isodienoestrol in solution rapidly lose their chromogenic power, while that of stilboestrol is maintained at its initial level for a comparatively long period. The stability of dienoestrol was tested in a number of solvents, and in every case the chromogenic power towards the antimony reagent decreased with increasing age of the solution.

\section{Application of Malpress's nitro reaction to the deter- mination of synthetic oestrogens in chloroform and. in ethylene dichloride solution}

Simultaneously with the above experiments, the chromogenic power of the ageing stock solutions of stilboestrol, dienoestrol, and isodienoestrol was measured by Malpress's method. Samples were withdrawn at intervals, the solvent evaporated at low temperature in a stream of nitrogen and the residue dissolved in glacial acetic acid. The subsequent procedure was as described by Malpress. The mean results of these experiments are shown in Fig. 5. The decrease in colour developed with in. creasing age of the solutions in the case of dienoestrol and of isodienoestrol is again clearly shown, although the actual decrease at any given age is not so great as with the antimony reagent. The lowest value for dienoestrol (at 16 days) was $53.5 \%$ of the initial value, whereas the antimony reagent showed only about $15 \%$ of dienoestrol to exist unchanged at this time.

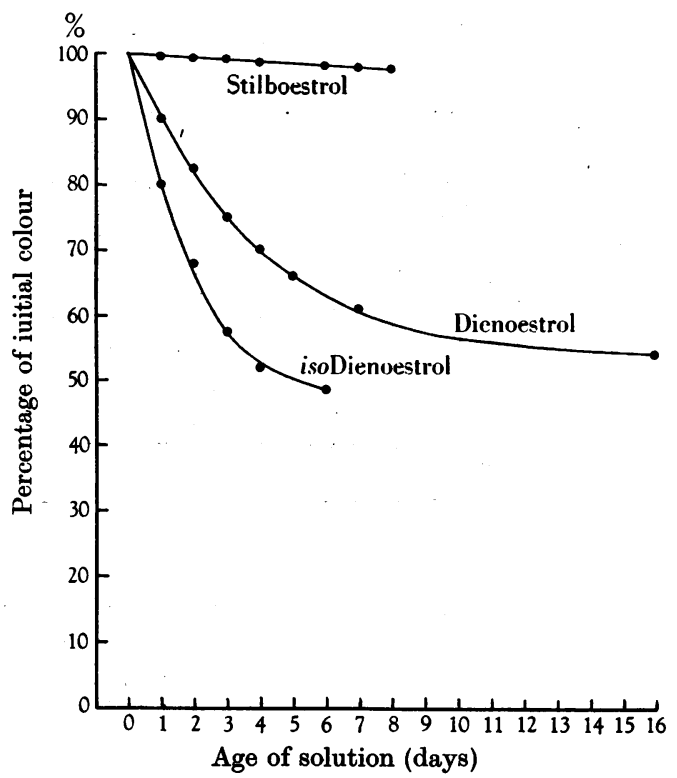

Fig. 5. Effect of age of solution of synthetic oestrogens on the Malpress nitro reaction. Chromogenic power expressed as percentage of initial colour value.

\section{Mechanism of the 'decay' of dienoestrol solutions}

It appeared probable that the explanation of the gradual loss of reactivity of dienoestrol towards antimony pentachloride might be a slow oxidation of the substance leading to disappearance of ethylenic double bonds. The integrity of these bonds is apparently essential for chromogenic power.

In order to test this possibility, solutions of dienoestrol in ethylene dichloride were prepared, and stored in the light and at room temperature but in the absence of air, achieved by thorough evacuation of the tubes containing the solution and subsequent sealing when all air had been displaced by solvent vapour. The same number of control (unsealed) tubes was stored under the same conditions. One sealed tube and one control tube were tested with antimony reagent at weekly intervals.

At the end of the experiment (21 days) no loss of chromogenic power had occurred in the dienoestrol in the sealed tubes, whereas the unsealed controls had shown the usual rapid 'decay'. It can be concluded, therefore, that the decay is caused by atmospheric oxidation of the oestrogen.

\section{Application of the antimony reaction to the estimation of synthetic oestrogens in extracts of human urine}

It was clear, from the experiments described above, that the problem of the detection and estimation of dienoestrol in human urine was likely to 
be a difficult one. The difficulties involved in the prevention of oxidation during the necessary hydrolytic and extraction processes appeared formidable. On the other hand, the proved stability of stilboestrol, and the high sensitivity of the reagent towards this oestrogen, suggested that it should be possible to obtain at least approximate measurements of the urinary excretion of stilboestrol in subjects undergoing treatment with this substance. Attention was therefore confined to urines likely to contain stilboestrol.

The complicating factor in the use of the antimony reagent on urine extracts is the presence of relatively large quantities of phenols. Small quantities of simple phenols (phenol or cresol) completely inhibit colour development. It was found, however, that the quantity of phenol present in the urine extracts could easily be reduced below the interference level by heating the extracts at $100^{\circ}$ in vacuo. Recovery experiments with known amounts of stilboestrol (1-10 $\mu$ g.), to which phenol or cresol had been added in amounts (5-10 mg.) comparable to those encountered in urine extracts, gave excellent results. The method finally adopted for investigating the stilboestrol content of urine was as follows:

(a) Unhydrolyzed urine. Fresh urine $(100 \mathrm{ml}$.$) was$ extracted with chloroform, the chloroform washed with water, dried, and distilled off in vacuo. The residue was treated as described below for the extract from hydrolyzed urine.

(b) Hydrolyzed urine. Urine (100 ml.) was acidified with $15 \mathrm{ml}$. of conc. $\mathrm{HCl}, 50 \mathrm{ml}$. of benzene added and the mixture refluxed for $3 \mathrm{hr}$. on the water bath. The benzene layer was then removed and replaced by a fresh $50 \mathrm{ml}$., and the mixture again refluxed for $3 \mathrm{hr}$. The combined benzene extracts were washed twice with water, the benzene separated, filtered and evaporated.

The residue was dissolved in $10 \mathrm{ml}$. of ethylene dichloride. $1 \mathrm{ml}$. of this solution was removed and diluted to $10 \mathrm{ml}$. with ethylene dichloride. This $10 \mathrm{ml}$. of solution served às a 'blank' for the colorimetric estimation; the urine extracts frequently had a red colour which contributed to the final red colour developed by the oestrogen, and it was necessary to correct for this.

A further $1 \mathrm{ml}$. of the original solution was transferred to a pyrex Thunberg tube which was then immersed in a boiling water bath and the solvent carefully evaporated at ordinary pressure. A vacuum was then applied (water pump) and the tube maintained in the bath for $15 \mathrm{~min}$. The top part of the tube was carefully heated with a free flame to prevent condensation of the phenolic distillate.

After cooling the tube, the contents were dissolved in $1 \mathrm{ml}$. of ethylene dichloride and treated with $9 \mathrm{ml}$. of antimony reagent. The colour was allowed to develop at $30^{\circ}$ for $15 \mathrm{~min}$. and then measured (against the blank solution described above).

Urines from ten different patients were examined by this method. Eight of these subjects were receiving oral therapeutic doses of $5-15 \mathrm{mg}$. of stilboestrol daily. Two subjects had been implanted subcutaneously with $100 \mathrm{mg}$. of stilboestrol. In none of the extracts (unhydrolyzed or hydrolyzed) was unequivocal evidence of the presence of stilboestrol obtained. The colour developed was in all cases anomalous (i.e. brownish instead of red). On the other hand, small quantities of stilboestrol added to urine (either in solution in organic solvents or in aqueous solution as the sodium derivative) before hydrolysis and extraction could be recovered with approximately $100 \%$ accuracy. It is possible that the brown colour developed in these extracts may be due to decomposition products of stilboestrol present in the urines, since it was not observed in control experiments with normal urines.

\section{DISCUSSION}

Stilboestrol and dienoestrol are both widely used as therapeutic oestrogenic agents. In clinical practice dienoestrol is often used in preference to stilboestrol. This preference appears to be based on the belief that dienoestrol causes fewer side effects (nausea and vomiting) than does stilboestrol. Although this may be so when the two oestrogens are administered orally in the same amounts it is by no means certain that under these conditions the same oestrogenic effect is obtained.

The most important result of the present work is the demonstration of the great difference in stability between stilboestrol and dienoestrol. While the former substance has considerable stability in solution and resists oxidation, solutions of dienoestrol undergo very rapid atmospheric oxidation. This oxidation leads to loss of chromogenic potency towards both the Dingemanse and the Malpress reagents, and at the same time there is a correspanding decrease in oestrogenic potency. Since this oxidative destruction occurs readily in a variety of solvents (including aqueous solvents) it would clearly be difficult to prepare solutions of dienoestrol of known oestrogenic potency for therapeutic purposes unless some antioxidant were incorporated in such solutions.

The attempts to demonstrate the presence of stilboestrol in the urine of subjects undergoing treatment with relatively large amounts of this oestrogen, which have been described above, must be regarded as preliminary experiments. However, if account is taken of the high sensitivity of the method used, the total amount of stilboestrol (conjugated or free) in these urines must have been very small. The urine extracts gave anomalous colours (brown). But if the total absorption of green light by such solutions is taken as representing the maximum amount of stilboestrol which could be present (an obvious overestimate), the total daily urinary excretion of stilb. oestrol in patients receiving a daily oral dose of 
$15 \mathrm{mg}$. did not exceed $5 \%$ of the dose given. Since this figure is, admittedly, an overestimate, the results indicate that, broadly speaking, none of the administered stilboestrol was present in the extracts. This does not, of course, imply that the urine did not contain oestrogenic substances. It is possible that metabolites of stilboestrol were present, still possessing oestrogenic activity, but whose structure precluded the formation of red-coloured products with antimony pentachloride. The formation of the anomalous brown pigments by such urine extracts may be significant in this connexion.

The negligible amounts of free stilboestrol found in the extracts of unhydrolyzed urine in the present experiments are possibly to be expected by analogy with other compounds and with the results of experiments with stilboestrol in other species. The main excretory product might well be a conjugated product. Some observations of Malpress are of interest in this connexion. Malpress (private communication) has so far found it impossible to estimate the ether-insoluble forms of stilboestrol in cow's urine, owing to the complete destruction of this oestrogen when hydrolysis by hydrochloric acid takes place in the presence of other urinary constituents. On the other hand, as he has shown (Malpress, 1946), hydrolysis of the glucuronide by hydrochloric acid in simple solution gives recoveries of the oestrogen which closely approximate those which can be calculated from postulates as to the action of hydrochloric acid on pure stilboestrol. The failure to demonstrate conjugated stilboestrol in the present experiments may be due to similar causes.

\section{SUMMARY}

1. The behaviour of stilboestrol, dienoestrol, and isodienoestrol in Dingemanse's antimony pentachloride reaction and Malpress's nitro reaction has been examined.

2. In solution in a variety of solvents, stilboestrol is stable, but dienoestrol and isodienoestrol are unstable. This instability of dienoestrol and of isodienoestrol in solution arises from their susceptibility to rapid atmospheric oxidation.

3. Attempts to demonstrate the presence of free or conjugated stilboestrol in the urine of subjects undergoing treatment with large therapeutic doses of this oestrogen failed to reveal the presence of significant amounts.

One of us (F.L.W.) is indebted to the Sir Halley Stewart Trust for a Fellowship and to the Anna Fuller Fund for a grant. Generous grants to the Chester Beatty Research Institute from the British Empire Cancer Campaign greatly assisted the work. We should also like to thank our colleagues on the Chemical Advisory Panel of the Committee on Oestrogens in Cancer (under the aegis of the Royal Society of Medicine and the British Empire Cancer Campaign) for much helpful advice and discussion. We are particularly grateful to Prof. E. C. Dodds, Dr W. Lawson, and Dr W. F. Short for the gift of compounds and to Dr Freda Herbert for supplying some of the urine extracts.

\title{
REFERENCES
}

Dingemanse, E. (1939). Acta brev. neerl. Physiol. 9, 118. Malpress, F. H. (1945). Biochem. J. 39, 95.

Malpress, F. H. (1946). Nature, Lond., 158, 790.
Smith, A. E. Wilder \& Williams, P. C. (1945). Nature, Lond., 156, 718.

Warren, F. L. \& Goulden, F. (1945). Biochem. J. 39, xliv.

\section{The Osmotic Pressure of Insulin Solutions}

\author{
By H. GUTFREUND, Biochemical Laboratory, University of Cambridge
}

(Received 28 April 1947)

Sjögren \& Svedberg (1931) examined solutions of crystalline insulin in the ultracentrifuge. From determinations of the sedimentation constant they concluded that it is a homogeneous protein, stable between $\mathrm{pH} 5$ and 7 . From sedimentation equilibrium measurements they calculated a molecular weight of 35,000. Polson (1937) determined the diffusion constant of insulin, and calculated from this $\left(D_{20}=8.2 \times 10^{-7}\right)$ and Sjögren \& Svedberg's sedimentation constant $\left(S_{20}=3.47 \times 10^{-13}\right)$ the molecular weight 40,900. From Crowfoot's (1938) crystallographic measurements the weight of the dry unit cell is about 36,000.* The unit cell has trigonal symmetry, and the molecular

* The value quoted by Crowfoot (1938) for the dry unit cell weight is 37,600 . This has been calculated on the assumption that the moisture contents of air-dried insulin crystals are $5 \cdot 35 \%$. Miller \& du Vigneaud (1937) pointed out the difficulties of obtaining accurate values for the moisture contents of insulin crystals and found $10 \cdot 2 \%$ as the result of repeated analyses. The present author analyzed five samples of air-dried insulin crystals and found variations between 10 and $12 \%$ for the moisture contents. Completely dried crystals, if left at room temperature, absorbed water until they contained from 10 to $11 \%$. 